\title{
A PRÁTICA DA PARTICIPAÇÃo MEDIADA EM COMUNIDADES MARGINALIZADAS NA INDONÉSIA
}

\author{
Kurniawan Adi Saputro \\ Faculdade de Média, Departamento de Fotografia, Instituto Indonésio das Artes Yogyakarta, Indonésia
}

Bari Paramarta Islam

Investigador independente, Indonésia

\begin{abstract}
RESUMO
O tema da participação tem sido frequentemente questionado em termos de abrangência, nomeadamente quanto ao número de membros de uma determinada sociedade que têm voz enquanto coletivo. Este artigo, ao invés de avaliar o nível de igualdade entre atores, tenta identificar práticas correntes que contextualizem o processo de participação, tornando-a, desse modo, possível e limitada. Foram analisados dois casos de estudo que envolvem comunidades marginalizadas, durante um projeto de cinema participativo: uma comunidade de fiéis de uma religião tradicional (penghayat), em Elu Loda, e uma comunidade de pessoas com necessidades especiais, em Salam Rejo. Estas comunidades foram observadas durante a sua participação em oficinas de cinema, entre outubro de 2018 e fevereiro de 2019. Foram entrevistados 14 participantes, dois facilitadores e um representante do patrocinador do programa. Além disso, os participantes e alguns membros da comunidade que estiveram envolvidos no processo foram convidados a responder a um inquérito criado com o objetivo de pôr a descoberto as suas práticas comunicativas relacionadas com a narração de histórias (storytelling), registos fotográficos e reuniões comunitárias (Elu Loda $n=49$, Salam Rejo $n=31$ ). Estudámos o modo como as histórias pessoais circulavam entre esses grupos e como alguns indivíduos usavam o cinema como veículo de apresentação da sua versão das histórias, enquanto a sua forma coletiva de contar histórias permanecia desligada do workshop (oficina). Percebemos ainda que a cultura formata o modo como algumas pessoas se tornam mais visíveis do que outras e como estas desenvolvem competências para se evidenciarem, o que abriu a porta à sua participação. Por fim, descobrimos que a imersão dos participantes na sua cultura e comunidade afeta os aspetos que despertam mais o seu interesse e por que razão: o saber técnico da oficina e/ou o conteúdo.
\end{abstract}

PALAVRAS-ChaVe

comunidades marginalizadas; média participativos; práticas mediáticas

\section{THE PRACTICE OF MEDIATED PARTICIPATION IN INDONESIAN MARGINALISED COMMUNITIES}

\begin{abstract}
The question of participation has often been asked as an issue of degree, namely how much members of a society are allowed to have a voice in their collective life. Rather than evaluating the degree of equality reached between actors, this article attempts to identify existing practices that contextualise participation, and thus enable and constrain it. Two case studies, involving marginalised communities in participatory film production, were analysed: a community of believers in a traditional religion (penghayat) in Elu Loda and a community of people with
\end{abstract}


disabilities in Salam Rejo. These communities were observed during their participation in film workshops, from October 2018 to February 2019. Fourteen participants, two facilitators, and one programme officer of the sponsor were interviewed. In addition, participants and a selection of community members who interacted with the process were invited to fill in a questionnaire designed to elicit their communicative practices in relation to storytelling, making pictures, and community meetings (Elu Loda $n=49$, Salam Rejo $n=31$ ). We studied how personal stories were circulated in these groups and how some individuals used the film as a channel to distribute their version of the stories, while still their collective way of storytelling was disconnected from the workshop. Second, we learned that culture shaped how certain people become more visible than the others and how these people developed skills to be more visible, which opened the door to their participation. Third, the participants' embeddedness in their culture and community affected what aspects they were inclined to participate in and for what reason: in the workshop's technical know-how and/or in the content.

\section{KEYWORDS}

marginalised communities; media-related practices; participatory media

Se eu fosse cega, toca os teus olhos

Se eu fosse surda, toca os teus ouvidos

Se eu fosse coxa, lava os teus pés

Ephphatha!

Porque eu sou tu

Tu és eu

Porque temos todos a mesma dignidade

Porque pertencemos ao mesmo plano

Este poema foi recitado por uma rapariga com perda auditiva enquanto ensaiava a sua intervenção para o "Dia Internacional das Pessoas com Necessidades Especiais". As palavras foram inspiradas por histórias da Bíblia, que as pessoas da sua comunidade conheciam bem da missa de domingo. O poema também pediu emprestadas algumas palavras ao material promocional do programa que patrocinou o filme em que estava envolvida. O poema é uma colagem, um mosaico de palavras já existentes, sagradas e promocionais. Cada palavra é retirada do seu contexto, num caso claro de intertextualidade, sendo o seu significado transferido para o novo texto, produzindo novos significados. É uma metáfora eficaz sobre os processos participativos, para os quais os intervenientes transferem as suas experiências e acumulação de conhecimento cultural, juntando tudo, depois, com a ajuda dos dinamizadores. Mas, ao mesmo tempo, seria pertinente perguntar: Estes participantes não eram já alguém antes do seu envolvimento no projeto de cinema participativo? Não tinham já feito algo antes disso? Este estudo é uma tentativa de dar resposta a estas questões. 


\section{PARTICIPAÇÃo MEdiada E O DEClínio da DEMOCRACIA}

A questão da participação tem sido colocada em termos de abrangência, nomeadamente saber até que ponto é permitido que os membros de uma comunidade ou grupo tenham voz enquanto coletividade. De um ponto de vista normativo, Arnstein (1969) questionou-se sobre o que era a participação e elaborou um modelo que se tornou um modelo clássico de participação dos cidadãos, por exemplo, no âmbito dos estudos e projetos de desenvolvimento. $O$ modelo de Arnstein coloca os cidadãos numa relação antagónica entre os poderosos e os que nada têm; a escada está colocada de forma vertical para que possamos aferir o nível de controlo que os cidadãos detêm no processo de tomada de decisões. No seu ponto de vista, apenas os três degraus mais elevados contam como verdadeira participação, enquanto que os outros seis degraus (mais abaixo) são vistos como apenas simbólicos ou indicativos de ausência de participação. O modelo é útil como ferramenta de avaliação e reflexão, mas também tem as suas limitações. De acordo com Arnstein, o modelo não leva em consideração, explicitamente, "as infraestruturas política, social e económica e a base do conhecimento, além das dificuldades de organização de um grupo de cidadãos representativo e responsável" (1969, p. 217).

Carpentier (2011a, 2011b) propõe um modelo diferente de participação, através do qual o acesso e a interação são definidos como pré-condições necessárias, mas continuam a ser encarados como distintos da participação. Para ele, o acesso e a interação não podem ser equiparados à participação uma vez que essas pré-condições não incluem o elemento essencial de partilha de poder. Consequentemente, Carpentier, no seu modelo AIP (Acesso, Interação, Participação) subscreve, ainda que de uma forma diferente, a abordagem de Arnstein, na medida em que também ele reserva o espaço da participação para lutas pelo poder "reais", uma consequência inevitável do facto de basearmos a participação na teoria democrática. Avisa, no entanto, que a participação nunca poderá ser considerada como um espaço fantástico onde as lutas pelo poder são resolvidas através de uma relação totalmente igualitária entre todos os atores. No contexto contemporâneo, a atenção recai na transformação das elites "a fim de permitir a partilha do poder" (Carpentier, 2011b, p. 26). A sua proposta é que foquemos a nossa atenção na análise de casos específicos, uma vez que estes processos participativos se "caracterizam pelo equilíbrio e lutas pelo poder em diferentes níveis, momentos e locais" (Jenkins \& Carpentier, 2013, p. 267). O objetivo é captar a "complexidade - e as contradições que a causam" do processo participativo (2013, p. 267). A complexidade, devido à sua natureza multidimensional, com diversos níveis e dinâmica, parece ser essencial para compreender este processo.

Carpentier (2016) aprofunda a sua estrutura analítica ao encarar a participação como um processo com diversos subprocessos, por vezes sem sobreposições nítidas entre os seus elementos. Para além de contemplar as suas características fortuitas, multidimensionais e complexas, o modelo leva em consideração "as guerras materiais e discursivas" (2016, p. 77), intrínsecas às lutas pelo poder. O resultado é um modelo com múltiplos elementos (Carpentier chama-lhes níveis) que consiste na análise 1) do contexto (processo e áreas nas quais se situa o processo); 2) atores; 3) decisões e 4) 
relações de poder. Sugere que se decomponha a situação participativa (a sua análise) em 12 subelementos. O modelo é mais complexo do que a escada de participação de Arnstein, ou do que o seu próprio modelo AIP. Está ajustado de modo a abordar as questões intrínsecas à análise da participação e a primeira tentativa de aplicação parece captar o que pretende retratar (Yüksek \& Carpentier, 2018). Do nosso ponto de vista, o ponto forte do modelo poderá passar a ser o seu ponto fraco uma vez que é demasiado descritivo, complexo, e, daí, poder ser mais útil em análises cujo investigador tenha um conhecimento profundo do contexto local. Reconhecemos o mérito de usar uma estrutura tão dinâmica e complexa; no entanto, convém recordar que, uma vez que a participação se localiza na interseção da teoria e da prática, seria provavelmente melhor criar um diálogo significativo entre as duas, usando para tal vocabulários menos abrangentes, fortemente orientados para preocupações e expectativas reais.

Dagron (2007) também ressalta este ponto, ao afirmar que os projetos participativos estão indissociavelmente ligados às vidas dos participantes. Do seu ponto de vista, ao refletir sobre o seu ativismo de décadas no campo dos média comunitários, a participação serviu para "referir uma grande diversidade de experiências" que podem confundir aqueles que "tiveram pouca experiência a nível local" (Dagron, 2007, p. 197). Além disso, ele deixa um aviso sobre o facto de "o exercício académico incluir alguns e excluir os restantes" e "não representar realmente o que está a acontecer no terreno" porque a participação lida com "processos de comunicação, ou seja, organismos sociais vivos" (Dagron, 2007, p. 198). Em vez de usar um modelo idealizado, ele defende modelos que descrevam "a luta dos média comunitários enquanto ferramenta de mudança social, educação, entretenimento, socialização do conhecimento, desenvolvimento económico, etc." (Dagron, 2007, p. 202).

De acordo com algum do trabalho desenvolvido pela teoria democrática, a melhor forma de os cidadãos aprenderem algo sobre a participação seria eles mesmos participarem em atividades cívicas (della Porta, 2013). De facto, foi o reconhecimento de que "a democracia está em crise" que levou alguns autores a estudarem o processo de participação (Couldry, Livingstone \& Markham, 2007; della Porta, 2013). Por exemplo, della Porta escreve que "salvar a democracia significaria ir além do modelo liberal, levando mais longe a reflexão sobre participação e deliberação dentro e fora das instituições" (2013, p. 2). A autora aponta a participação como uma das duas características definidoras da democracia, sendo a deliberação a outra. Couldry, Livingstone e Markham também "procuram pré-condições sociais para um esmorecimento do envolvimento" (2007, p. 14). Estes estudos refletem a preocupação profunda e de longa data dos autores quanto ao declínio do envolvimento político dos cidadãos conforme indica a baixa taxa de participação eleitoral.

No nosso estudo, seguimos em grande medida a direção apontada por Dahlgren (2003), a propósito do estudo da cultura cívica, o que, por seu lado, diz respeito ao modo "como as pessoas se tornam cidadãos" (2003, p. 153). Tal centra-se no quotidiano dos cidadãos, em vez de se focar nos procedimentos formais da política institucional. Esta abordagem está em linha com o que Postill (2010) define como "os conjuntos de 
atividades que os humanos desempenham com graus variáveis de regularidade, competência e talento" (Postill, 2010, p. 1). Pedimos emprestada a noção de "prática relacionada com os média" a Postill e usamo-la - muito livremente - aprofundando a sua definição de média. Este aprofundamento significa que vemos o teatro (com a atenção focada na narração de histórias) e os documentos escritos (em particular referentes às reuniões comunitárias) como média relevantes. Estas práticas relacionadas com os média foram reunidas em duas oficinas sobre cinema participativo (ver abaixo), tornando-se o nosso objeto de estudo. Através da análise destas oficinas, tentamos captar a complexidade da participação num determinado contexto na Indonésia.

\section{A PARTICIPAÇÃo Na Indonésia}

Nos últimos 20 anos, a Indonésia sofreu uma transformação radical, passando de uma ditadura para uma democracia. Entretanto, a participação política, medida através da filiação partidária, mostrou uma queda acentuada, semelhante à de muitas democracias ocidentais. Muhtadi (2018) demonstra que a filiação partidária caiu de cerca de 10\%, em 2004, para 1,5\%, em 2014. No entanto, a participação dos eleitores manteve-se estável nos $72 \%$ quando comparada com eleições anteriores (Nurhasim, 2014), tendo aumentado para os $81 \%$ nas eleições presidenciais de 2019. Estes números indicam que participação democrática na Indonésia sofreu um certo declínio, mas também que os seus cidadãos ainda acreditam nos processos e na ideia de democracia. Existem, contudo, algumas diferenças quando comparamos o desenvolvimento político na Indonésia e o das democracias ocidentais. A trajetória atual da democratização indonésia não começou com o surgimento de uma classe média forte, politicamente independente e progressista, ou qualquer "mudança estrutural à frente da democracia" (Törnquist, 2013, p. 6) como defenderam alguns teóricos. Emergiu antes da luta entre elites e entre essas e uma série de "atores dissidentes, movimentos sociais, organizações da sociedade civil" (Törnquist, 2013, p. 11).

De entre as diversas críticas lançadas por Törnquist contra as avaliações democráticas baseadas no modelo liberal, uma será particularmente relevante, nomeadamente a crítica à "superioridade do modelo democrático liberal (e a respetiva constituição dos demos e dos assuntos públicos)" (2013, p. 12). Ele escreve que o modelo ignora outras instituições, "regras e regulamentos relacionados com a democracia participativa, o debate nas comunidades muçulmanas ou comunidades regidas pelo direito consuetudinário" (Törnquist, 2013, p. 13). O que Törnquist defende é semelhante à posição desenvolvida por Menchik (2016) no seu estudo sobre a tolerância nas três maiores organizações islâmicas da Indonésia. Mais especificamente, Menchik defende na sua obra que a democracia indonésia poderia desenvolver-se sem liberalismo. O Estado indonésio é, de acordo com Menchik (2016, p. 12), "um híbrido religioso-secular que promove valores como a crença em Deus e a filiação comunitária como principal objetivo da sociedade civil e do Estado". A nossa intenção, aqui, não é repetir o argumento de centralidade da religião na Indonésia, mas libertar o conceito de participação das suas raízes na teoria política 
liberal, para a qual os direitos individuais e as identidades são da maior importância e servem de base ao interesse dos cidadãos em participar nos processos de tomada de decisões. Acompanhamos e desenvolvemos o argumento de Menchik quando ele afirma que a separação estrita entre assuntos individuais e comunitários não é um fenómeno universal e que, em muitos locais, as preocupações da comunidade se sobrepõem às dos indivíduos. Para além disso, o envolvimento dos indivíduos e a utilização das suas competências em atividades comunitárias e culturais preparam-nos para a sua participação no sentido maximalista do termo (Carpentier, 2011a). O que pretendemos argumentar aqui é muito semelhante à visão de Dahlgren da cultura $(2003,2006)$ e da vida quotidiana enquanto "campo de treino" (Dahlgren, 2006, p. 272) para a participação. A diferença assenta na ênfase que colocamos em práticas específicas aceites e reforçadas pela comunidade e que dão aos participantes a motivação, identidade e competências para poderem envolver-se a fundo nos processos participativos.

No nosso estudo, pretendemos focar-nos nos vídeos participativos que têm sido usados na Indonésia desde os anos 80 do século $X X$, por ativistas e profissionais de média, como método de capacitação dos cidadãos. O Kunci Cultural Studies Center and Engage Media (2009) investigou o panorama dos vídeos participativos e descobriu que era escasso, consistindo apenas em três organizações especializadas na sua produção. No entanto, muitas outras oficinas foram realizadas por organizações da sociedade civil criadas para esse fim específico, embora frequentemente não exista qualquer documentação sobre os mesmos. O projeto de vídeo participativo que analisámos fazia parte de um programa mais vasto no qual o Ministério Indonésio da Segurança Social tinha vindo a trabalhar em parceria com a Asia Foundation, com o apoio financeiro do governo australiano, a fim de abranger todos aqueles que se encontravam estruturalmente marginalizados, das mais diversas formas.

O responsável pelo programa respondeu que, na realidade e relativamente a este projeto, estavam a experimentar este meio participativo uma vez que nunca tinham usado o cinema no seu trabalho (entrevista, 13/10/2018). A experiência foi motivada pelo sucesso inesperado de uma oficina de escrita acerca da história da aldeia de Salam Rejo, onde viviam penghayat kepercayaan, crentes de uma religião tradicional e "não oficial"'. Essa oficina, realizada em 2017, teve uma duração de mais de seis meses e envolveu 15 adolescentes que receberam formação para entrevistar pessoas com informações essenciais sobre a história de certos monumentos, práticas culturais e membros fundadores da sua aldeia. Tal resultou numa publicação local, sob a forma de livro de bolso, que foi distribuída gratuitamente pelos aldeãos. Apesar de alguma ansiedade provocada por atrasos e desacordos acerca da precisão da narrativa e da escolha dos informantes, a versão final do livro foi aceite com o reconhecimento dos órgãos de administração da aldeia e das suas principais figuras. O processo de entrevistas, que permitiu que os adolescentes interagissem com pessoas fora dos seus círculos, e as reuniões com diferentes

\footnotetext{
' $\mathrm{Na}$ Indonésia existem seis religiões oficiais (agama), incluindo a islâmica e o protestantismo, mas também um extenso número de religiões não oficiais (kepercayaan). Estas últimas são, por vezes, marginalizadas (consultar Crouch, 2016; Mutaqin, 2014).
} 
grupos organizados para debater os resultados, criaram um sentimento de união. O líder religioso local teve um papel importante no projeto, tendo providenciado informação relativa à história de Salam Rejo e sido mencionado no livro como pertencendo ao círculo de anciãos da aldeia. Depois de concluído, o livro foi altamente elogiado por outras aldeias pertencentes à mesma "regência" (unidade administrativa/territorial)² e o representante máximo da aldeia foi frequentemente convidado a participar em palestras acerca do projeto e a fazer sugestões sobre projetos semelhantes. Os crentes participaram nas consultas sobre o desenvolvimento no âmbito da regência e trabalharam com outros grupos (maioritariamente islâmicos, a religião com maior expressão na Indonésia), a fim de desenvolverem iniciativas económicas relacionadas com turismo e restauração.

O projeto do livro inspirou o responsável pelo programa a considerar outros média no que diz respeito à documentação e apresentação dos efeitos provocados pelas fricções e exclusões na vida quotidiana dos grupos marginalizados. É difícil apresentar esta realidade de forma adequada nos relatórios do programa, uma vez que se concentram nos indicadores e nos objetivos do mesmo, independentemente do nível de sucesso obtido em cada um deles. Se não tivéssemos reconhecido e não tivéssemos consciência de que alguns grupos foram impedidos de participar, ou afastados de serviços públicos, por força da sua identidade, e não tivéssemos tornado os conflitos e a tolerância visíveis, as suas vozes não teriam sido ouvidas. Contar a sua história sob a forma de livro, e depois filme, foi visto como uma forma de luta porque, em certos casos, essa luta não era apenas estrutural, mas também simbólica.

\section{O ESTUDO DE CASO}

A Asia Foundation fez parceria com a ONG Tumbuh Sinema Rakyat [Tumbuh o Cinema do Povo] para o recrutamento de comunidades penghayat em Salam Rejo, pertencente à regência de Kulon Progo, na ilha de Java, e de comunidades de pessoas com necessidades especiais da aldeia de Elu Loda, situada na regência de Sumba Barat [Sumba oeste], na ilha de Sumba. As oficinas prolongaram-se de meados de outubro 2018 até fevereiro de 2019. O formato de longa-metragem foi escolhido porque a sua duração permitia a inclusão de diferentes pessoas e a representação das várias circunstâncias nas quais se manifestaram diferentes desafios. Contudo, esse formato também apresentou desafios particulares, relativamente à narrativa e a nível técnico. Assim sendo, os participantes apenas puderam estar presentes nas fases de pré-produção e produção, enquanto que a fase de pós-produção ficou totalmente a cargo do Tumbuh Sinema Rakyat. O que motivou essa decisão foi o facto de o patrocínio acarretar limitações de tempo e por se considerar que os participantes não possuíam as competências técnicas necessárias para a fase de pós-produção.

Uma das oficinas foi realizada com 14 membros com e sem necessidades especiais da comunidade de Elu Loda, na regência de Sumba Ocidental. É uma região relativamente subdesenvolvida e mal servida quanto a serviços, quando comparada com a

\footnotetext{
${ }^{2}$ As regências são unidades administrativas indonésias de segundo nível, imediatamente abaixo de província.
} 
parte oeste do país, onde se concentra o desenvolvimento económico. A aldeia de Elu Loda repousa sobre colinas cársicas e a escassez de água fresca significa que as pessoas, incluindo crianças, têm de andar ou usar as suas motocicletas para ir buscar um ou dois bidões de água. As casas foram construídas a partir de materiais baratos, tais como tijolos de betão para as paredes e zinco para o telhado, em vez de madeira e folhas de palmeiras, materiais usados no passado. A aldeia é bastante recente; tornou-se uma entidade administrativa autónoma há apenas sete anos, ao separar-se de uma aldeia maior. A maioria dos aldeãos vive da terra, do cultivo de milho, arroz de regadio, soja e raízes de caladium, quase exclusivamente para sua própria subsistência. Além disso, criam porcos, sem intuito comercial, os quais se podem encontrar em todas as casas e são usados também em rituais. Uma vez que o seu dia-a-dia gira à volta da terra, que não precisa de um cuidado extremo, eles vivem, de um modo geral, de forma despreocupada, sobrando-lhes muito tempo para socializar.

A segunda oficina teve lugar em Salam Rejo e envolveu 13 pessoas, penghayat e não penghayat. Salam Rejo tem o aspeto característico de uma comunidade em plena transição, de um modo de vida rural e tradicional para um modo de vida urbano e moderno. De um modo geral, as casas foram construídas usando componentes manufaturados, tais como cimento, vidro, tijolos de betão, aço e cerâmica. A maior parte dos residentes já não depende da terra como forma de subsistência. São operários, artesãos, trabalhadores contratados pelo governo local ou pessoas que prestam diferentes tipos de serviços. O facto de muitos dos participantes ainda serem jovens significa que frequentavam a escola na sua regência e a universidade em Yogyakarta, capital da província, deslocando-se nas suas motocicletas através da macia estrada de asfalto que ligava a sua aldeia a outras partes da província. O seu quotidiano seguia o ritmo das horas de trabalho urbano, das oito da manhã às quatro da tarde, o que tornava muito difícil arranjar um horário adequado para a oficina.

\section{As OFICINAS}

As oficinas começaram com a aprendizagem de conceitos básicos sobre como contar histórias usando meios audiovisuais, tendo de criar um enredo simples. Em seguida, os participantes aprenderam a contar uma história, escrevendo a sua própria ou "entrevistando" outros participantes e escrevendo as suas histórias e vice-versa. As histórias pessoais estavam relacionadas com o tema da oficina, nomeadamente a inclusão na sociedade. Depois, o facilitador-realizador analisou todas as histórias, e os autores (designados donos das histórias) com maior potencial foram convidados para uma breve oficina a fim de fornecerem mais detalhes. O facilitador usou, então, todas essas diferentes histórias para compor uma narrativa coerente que incluiu mais do que um enredo. Usou as ideias centrais, as personagens principais das histórias dos participantes, mas inseriu-as num novo universo narrativo. Em vez de se tratar de um guião para um filme na verdadeira aceção da palavra, o resultado final do processo constituiu o tratamento de uma história, incluindo cenas que especificavam as personagens, as suas ações, localização e tempo, sem diálogo. Este método tinha como objetivo reduzir o tempo e 
orçamento da produção e a carga de trabalho dos participantes. Além disso, esta abordagem envolveu a utilização de personagens reais (donos das histórias), locais reais (com alterações mínimas), a língua local e os seus próprios guarda-roupas e caraterização.

Os donos das histórias foram (parcialmente) tornados anónimos no filme, tendo-se recorrido a nomes novos e fictícios. No entanto, os outros participantes e a comunidade sabia que o filme era sobre as suas vidas reais. Afinal, o filme tinha como objetivo chegar a um público mais alargado e a oficina teria como consequência a revelação da vida privada dos participantes. Além disso, como este artigo irá realçar mais adiante, os filmes constituíam uma oportunidade que as comunidades marginalizadas poderiam (e iriam) usar em seu benefício. Os locais foram escolhidos de entre algumas das áreas de onde eram originários os participantes e selecionados com base em quão convincentes eram em relação à história e personagens, juntamente com considerações artísticas relativas ao filme. Por exemplo, alguns dos planos de exterior foram realizados na região de Sumba, a qual é conhecida pela sua vasta savana, céu azul e ambiente árido, para que as cenas do filme nos levassem a crer que tinham sido filmadas nessa ilha, tendo os planos assumido também uma dimensão estética. Para além disso, a língua local foi usada em ambos os filmes, ainda que na região de Sumba nem todos os facilitadores a falassem, o que significou que tiveram de recorrer a um intérprete local, a fim de que este conferisse os diálogos, e de confiar mais na autenticidade das expressões dos atores. O guarda-roupa e caraterização naturais, por sua vez, também criaram um aspeto mais local e conferiram maior credibilidade às personagens, embora, por vezes, os atores tenham necessitado de alguma orientação sempre que ficavam demasiado entusiasmados e se vestiam de forma algo exagerada.

\section{RECOLHA E ANÁLISE DE DADOS}

Através deste estudo, pretendemos saber quais e de que forma as práticas comunitárias estão relacionadas com as oficinas sobre cinema participativo. Para obtermos um conhecimento mais profundo sobre as comunidades e adequarmos a oficina à vida diária dos participantes, foram efetuadas algumas observações durante os quase quatro meses do processo. O primeiro autor deste artigo observou a oficina realizada em Salam Rejo, desde a preparação até à produção (tendo a sua participação sido mínima), enquanto que o segundo autor observou as oficinas de Elu Loda e Salam Rejo, tendo participado moderadamente como membro temporário da equipa e membro do elenco com um pequeno papel. Durante as observações, os autores tiraram notas sobre os processos e conduziram entrevistas aos participantes, na sua maioria individuais e semi-estruturadas $(n=14)$, questionando-os quanto às suas experiências prévias relacionadas com os média (narração de histórias, registos fotográficos e reuniões comunitárias) e quanto à forma como as competências adquiridas tinham sido, ou iriam ser, incorporadas nas suas vidas. Os entrevistados foram escolhidos de acordo com a intensidade da sua participação nas oficinas e a sua disponibilidade. Devido às limitações linguísticas dos autores, os informantes de Elu Loda foram entrevistados em indonésio, o que, para 
alguns, se revelou particularmente difícil, enquanto que os informantes de Salam Rejo foram entrevistados quer em indonésio, quer em javanês, dependendo do que fosse mais fácil para eles. Além disso, entrevistámos e debatemos ideias, muitas vezes em cenários informais, com o realizador, com um dos facilitadores do projeto e com um dos funcionários mais graduados da organização patrocinadora. Foram realizadas diversas entrevistas de acompanhamento, através de mensagens privadas, com o objetivo de verificar e obter todos os pormenores possíveis relativamente às nossas observações.

A entrevista e a observação são métodos de recolha de dados comuns aos estudos sobre participação nos e através dos média (ver, por exemplo, Carpentier, 2011a; Evans et al. 2009; Gutberlet, 2008; Mistry, Bignante \& Berardi, 2014; Singh, High, Lane \& Oreszczyn, 2017). Alguns autores usaram também a escrita de diários para ganhar conhecimento sobre a experiência dos sujeitos quanto à dimensão temporal (Couldry et al., 2007; Shaw, 2016). Os métodos de inquérito são menos usados neste tipo de estudos, possivelmente devido ao seu objetivo de revelar informações sobre as experiências dos sujeitos em vez de retratar as suas características gerais (em contraste com, por exemplo, Couldry et al., 2007). Neste estudo, foi usado um inquérito para melhor compreender as práticas das comunidades alargadas onde se realizaram os dois projetos de vídeo participativo.

Os participantes e alguns dos membros da comunidade que interagiram com/no processo foram convidados a responder a um questionário concebido para obter informações sobre os seus hábitos de contar histórias, de registos fotográficos e reuniões comunitárias (Elu Loda $n=49$, Salam Rejo $n=31$ ). Foi usada uma amostra de conveniência para selecionar os membros da comunidade que viviam próximo do local de filmagens e que frequentavam reuniões comunitárias. Isto resultou em participantes com características semelhantes em termos de género, idade e formação académica, apesar de haver diferenças entre as duas aldeias. Por exemplo, em Elu Loda os participantes selecionados eram mais velhos $(M=38)$ do que os de Salam Rejo $(M=26)$. Esta diferença também se aplicou aos participantes na oficina. A amostra de conveniência não foi concebida, e não pode reivindicá-lo, com o intuito de representar toda a população, mas o inquérito serviu de base para sustentar a nossa interpretação. Os temas do questionário $(n=26)$ foram agrupados em perguntas sobre hábitos de oralidade e de escrita, nível de envolvimento na comunidade e competências de multimédia, nomeadamente fotografar e gravar vídeos.

Foram analisados dados numéricos para descrever as práticas da comunidade relacionadas com os média. Além disso, as transcrições das entrevistas e as notas de campo foram sistematicamente tratadas para se perceberem as práticas mediáticas das duas comunidades antes da realização da oficina e a forma como incorporaram as competências adquiridas durante a mesma. Uma vez que a nossa análise está incluída no projeto da oficina, os resultados que obtivemos aplicam-se maioritariamente aos participantes e não à comunidade em geral. 


\section{PARTiCipaÇão COMUnitária E PRÁticas no ÂMbito dos mÉdia}

Com base no inquérito realizado em ambas as comunidades, ficámos com uma ideia geral sobre as suas semelhanças e diferenças, em termos de como os membros da comunidade participam na resolução de problemas comuns.

As nossas observações iniciais tornaram claro que os membros da comunidade em Elu Loda e Salam Rejo se concentravam naturalmente em problemas que afetavam as suas próprias comunidades e diziam respeito aos seus ambientes sociais. As respostas ao questionário mostram claramente que os encontros com os familiares mais próximos e vizinhos contavam com as atividades mais frequentadas (ver Gráfico 1). Ligeiramente menos frequentes, mas ainda na categoria de "frequentemente", estavam os encontros comunitários e reuniões na aldeia, o que significa que para os membros de Elu Loda e Salam Rejo as suas comunidades tinham igual importância. Ao compararmos ambos os casos, os membros da comunidade de Elu Loda parecem ter tido melhores resultados relativamente às atividades comunitárias. Contribuíram ativamente com sugestões e seguiram os processos de tomada de decisões durante reuniões comunitárias, enquanto que os membros da comunidade de Salam Rejo, ainda que tenham escolhido estar presentes, mostraram-se menos ativos. Tal poderá ficar a dever-se ao facto de os inquiridos em Salam Rejo serem mais jovens $(M=26)$ e, por esse motivo, não se considerarem membros por inteiro da sua comunidade, ao passo que os participantes de Elu Loda, sendo mais velhos $(M=38)$, tinham uma maior probabilidade de se sentirem mais envolvidos na vida da comunidade.

Encontros presenciais e formas imediatas de interação continuaram a ser os meios fundamentais de participação na vida pública, enquanto que outras práticas relacionadas com os média foram menos usadas. Os inquiridos em Elu Loda escolheram a opção "às vezes" sobre escrever acerca de questões de ordem pública bem como sobre o facto de alcançarem um público limitado. Pensar em chegar a públicos mais alargados e gerais para discutir esse tipo de questões estava para além dos limites do seu quotidiano. Com base nas nossas observações e dados do inquérito, sabemos que usavam telemóveis para navegar e conversar no Facebook e serviços de mensagens privados, fruto da recente instalação de serviços de telecomunicação, para além de assistirem a telenovelas em conjunto à noite, devido ao número limitado de aparelhos de televisão na aldeia. As observações e entrevistas conduzidas pelos autores revelaram que pareciam mais interessados em telenovelas do que noticiários. Os inquiridos em Salam Rejo mostraram-se ligeiramente menos interessados na participação mediada acerca de assuntos de ordem pública (Couldry et al., 2007) do que os de Elu Loda. Os inquiridos de Salam Rejo usavam às vezes os seus telemóveis para tirar fotografias e gravar vídeos das imediações ou durante ocasiões especiais, mas raramente para assuntos do foro público. Iremos explorar as suas razões para tal, mas o inquérito deixou claro que o acesso e a interação (Carpentier, 2011a, 2011b) com uma grande diversidade de média deixara de ser um problema para os inquiridos de Salam Rejo, mas que a participação em assuntos públicos ainda estava para além da sua atenção e interesse. 


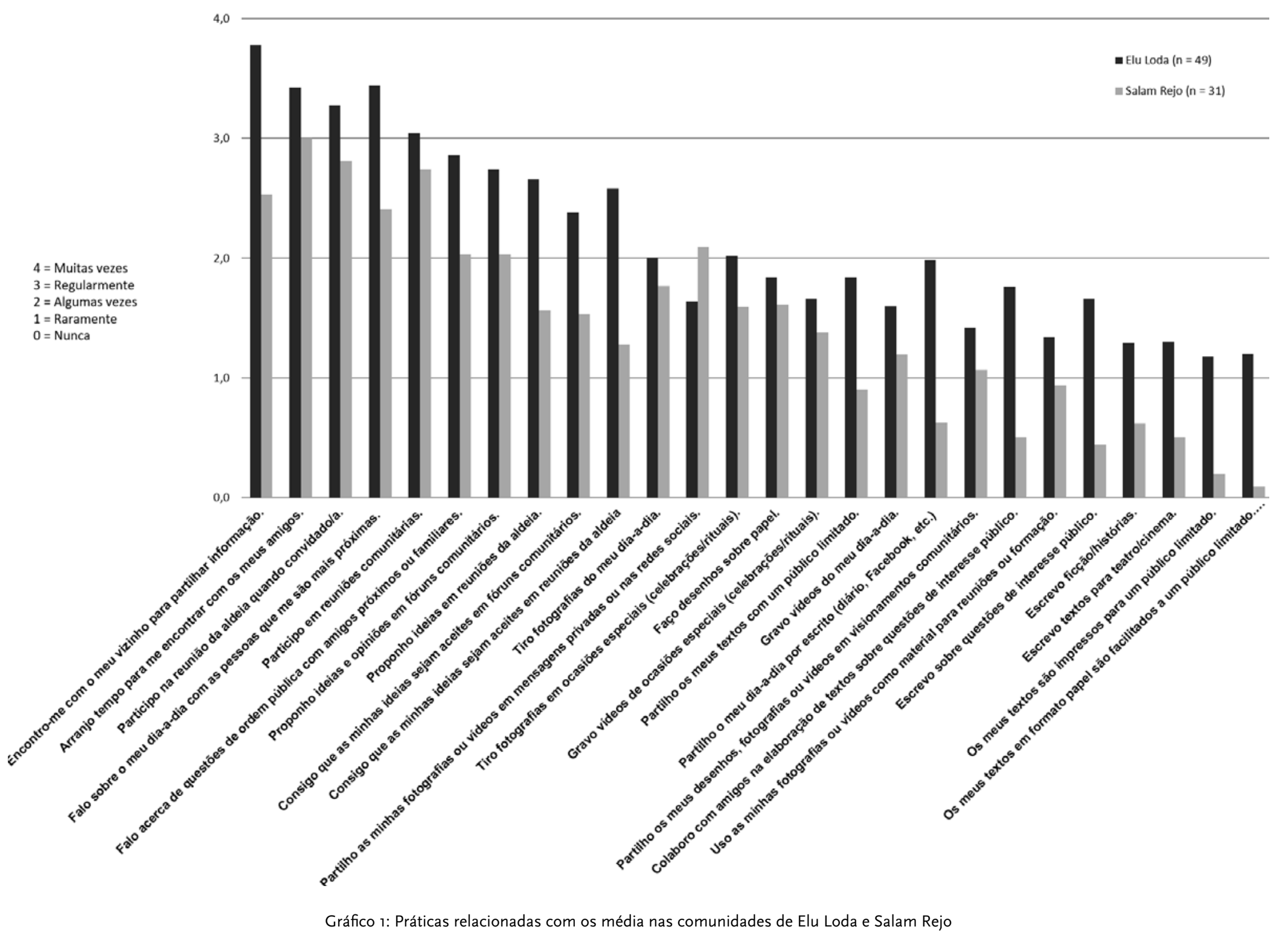


Com base nos dados do inquérito, é seguro inferirmos que as práticas de média nas quais os inquiridos se envolveram foram determinadas pela sua vida comunitária, em especial no caso de Elu Loda. Do ponto de vista geográfico, Elu Loda também se encontrava mais "isolada" da cidade; embora já estivesse ligada à capital da regência, as atividades económicas estavam mais orientadas para a vida comunitária, ao passo que as mantidas com a cidade eram escassas. Por outro lado, Salam Rejo estava ligada económica e geograficamente a Yogyakarta e outras regências da província com infraestruturas melhores e mais abrangentes. Por este motivo, e também porque os inquiridos de Salam Rejo eram na sua maioria jovens, não se deixavam definir tanto pela sua vida em comunidade. Embora os seus resultados quanto à intensidade tenham sido diferentes, em ambos os casos as práticas relacionadas com os média não se baseavam apenas em preferências de indivíduos sem ligação entre si, como acontece em sociedades mais urbanas e ocidentalizadas. Pelo contrário, essas práticas foram informadas através da comunidade sobre o que era considerado relevante ou não, e sobre o que era visto como normal ou não. Por exemplo, era completamente implausível que os membros da comunidade de Elu Loda se tornassem youtubers ou vloggers noutras plataformas, embora as ferramentas técnicas e as infraestruturas o permitissem, pelo menos até um certo ponto. O que faltava era a motivação - ninguém o encorajava ou apreciava, pelo menos nesse momento - para experimentar essas novas formas de expressão e de contacto com (potenciais) públicos (que podiam ter origem maioritariamente no exterior). Essa atitude diferia da adotada pelos jovens de Salam Rejo que não viam nada de extraordinário em ser-se youtuber, havendo até um participante que tentava, no momento, tornar-se um. Ainda assim, a sua prática cinematográfica mais comunitária tinha como propósito que fossem vistos pelos seus amigos na aldeia, ainda que fossem carregados no YouTube. Outro indicador do seu sentido de comunidade, e dos limites do seu campo de ação, era que todos os vídeos amadores tinham sido filmados nas imediações da sua aldeia e retratavam a sua própria comunidade.

As diferenças entre as duas comunidades acerca dos seus média preferidos, mas com semelhanças quanto aos limites da sua atenção, sublinham a questão da "participação em quê". Os tipos de práticas que as comunidades aceitam como normais, ou até desejáveis, servem como ponto de referência que indivíduos socializados devem considerar, aceitar, modificar, ignorar ou rejeitar. Não se trata de um argumento a favor do determinismo cultural, segundo o qual a cultura é $a$ força subjacente que determina identidades, planos e comportamentos. Mas também não é razoável pensar nos indivíduos como desligados dos seus contextos sociais e criadores individuais das suas predisposições, gostos, subjetividades e valores. Pelo contrário, nós defendemos a via do meio, pressupondo que, olhando através da lente das práticas relacionadas com os média conseguimos ver a participação como parte de processos mais alargados, e não como casos isolados, com processos divididos e que se desdobram numa dimensão temporal mais longa. O conceito de prática concentra a nossa atenção no que é um compromisso realmente estruturado, assumido e estável com o mundo (Postill, 2010). Em vez de analisarmos a luta entre detentores de poder assimétricos, procuramos essa 
assimetria no que diz respeito às competências que os indivíduos apresentam em práticas regulares muito antes dos processos participativos em análise terem acontecido.

Essas práticas estão divididas em três categorias, cada uma delas concentrando-se em aspetos particulares relevantes para a produção de filmes participativos. Em primeiro lugar, a produção interessa-se pela história, uma vez que esta é essencialmente o que liga os planos entre si (com as suas imagens e sons) dando origem ao filme. No caso específico destas oficinas, e devido ao método escolhido para recolher pedaços de história das experiências dos participantes e tecê-los de maneira a formar uma narrativa mais extensa, é importante analisar a prática comunitária de contar histórias pessoais. Em segundo lugar, a forma como os indivíduos encarnam as personagens e se apresentam a si próprios, para serem vistos pelos outros, é importante para entender como os atores amadores atuam com sucesso nestes filmes. Finalmente, a sua prática de participação em reuniões comunitárias é analisada a fim de percebermos as escolhas que fizeram em relação à forma como querem ser representados no filme. Os dados destas diversas análises resultam das notas de campo e das entrevistas semiestruturadas realizadas com os participantes e membros da equipa da oficina.

\section{HiSTÓRIAS PESSOAIS E NARRAÇÃo COLETIVA DE HISTÓRIAS}

Viver numa sociedade comunitária significa partilhar com os outros mais daquilo que normalmente consideramos ser privado, incluindo bens, comida, tempo e histórias pessoais. $\mathrm{O}$ ato de partilhar histórias pessoais não tem de ser deliberado, uma vez que a rede de ligações entre os membros da comunidade costuma ser suficientemente densa para permitir que pedaços de informação circulem até às periferias. Este ponto foi corroborado por alguns participantes; afirmaram não gostar ou não partilhar facilmente as suas histórias pessoais, mas os facilitadores da oficina foram capazes de obter pormenores sobre as mesmas relativamente a quase todos os elementos do grupo (facilitador masculino, entrevista, 21/12/2018). O principal problema dos "donos" dessas histórias não era a sua distribuição, uma vez que não era evitável nem passível de ser interrompida. O problema era que sentiam que não tinham controlo sobre as suas histórias. Contudo, a narrativa do filme, a qual foi urdida com as suas histórias pessoais, significava uma oportunidade. Tal foi exemplificado por uma participante: o filme permitiu que ela contasse "a verdadeira história da sua [vida]" e que o que ela ansiava por contar foi "finalmente ouvido" (participante feminina, entrevista, 10/1/2019). Outra participante também acabou por confiar a história que havia tentado guardar para si, embora a observação posterior tenha confirmado que os outros já a conheciam, pelo menos parcialmente (participante feminina, entrevista, 22/11/2018). Durante a oficina, os facilitadores tenderam a gravitar mais à volta daqueles que revelavam mais acerca de si próprios, uma vez que isso lhes dava mais material com o qual trabalhar para produzir um enredo mais completo. Os participantes que contribuíram com as suas histórias pessoais estavam conscientes de que o filme seria visto por estranhos e públicos anónimos. Tal facto causava-Ihes ansiedade, o que num dos casos levou a que a 'dona' da história, uma mulher divorciada, negociasse com o realizador, após a reunião, que partes deveriam 
ser incluídas e a forma como seria retratada. Na verdade, tinham composto a sua própria versão da história durante a oficina, mas o realizador acrescentara frequentemente elementos para tornar as personagens mais credíveis e relacionáveis com os públicos. Estes acrescentos não eram necessariamente baseados na realidade porque o resultado final iria ser apresentado e publicitado como ficção. Esta tensão entre participantes e facilitadores da oficina era uma questão persistente, a qual, neste caso em particular, foi resolvida (com a concordância de ambas as partes), mas revelou a necessidade de um enquadramento deliberativo e participativo mais desenvolvido para resolver este tipo de discrepâncias e tensões de uma forma mais estruturada.

Ao nível coletivo, emergiram semelhanças e contrastes interessantes entre as comunidades de Elu Loda e Salam Rejo, incluindo quer os membros marginalizados, quer os não marginalizados. Estas duas comunidades haviam desenvolvido algumas práticas que podiam usar para falar de cada uma delas. A comunidade de Elu Loda era relativamente homogénea relativamente à sua prática religiosa, tendo a igreja Protestante como instituição principal. Como parte dos seus rituais religiosos, por exemplo, durante as celebrações da Páscoa e do Natal, produziam breves peças baseadas em passagens relevantes da Bíblia. Os participantes da oficina expressaram o seu contentamento em interpretar papéis nessas peças, mas também a sua dificuldade em tentar memorizar os diálogos. A mesma narrativa cultural foi desenvolvida pela comunidade de Salam Rejo, sob a forma do livro de história local mencionado anteriormente, e que tratava das suas origens, dos seus locais de memória coletiva e dos seus membros fundadores. O livro tornou-se a base das suas celebrações culturais sucessivas e esforços para promover a inclusão, tais como o Festival Nacional de Sabedoria Local e o dia anual da aldeia. Contudo, este potencial permaneceu inexplorado em ambos os filmes. O filme da oficina não usou os elementos relacionados com a peça religiosa de Elu Loda, nem as suas formas artísticas, nem a história. As anteriores experiências de representação dos participantes (na sua peça local) não foram exploradas ou usadas posteriormente. O mesmo aconteceu com a história local de Salam Rejo. Embora a oficina de escrita tenha sido bem-sucedido ao permitir que os participantes avançassem com uma agenda mais inclusiva, as suas histórias e personagens ricas não foram incorporadas no filme.

Esta foi uma oportunidade perdida uma vez que a comunidade de Elu Loda ainda continua a produzir estas peças dramáticas. Se tivessem sido usadas e adaptadas ao filme, a comunidade poderia ter aproveitado a sua experiência na oficina para desenvolver as suas peças religiosas. Esta seria uma alternativa mais realista, do que fazerem mais filmes sozinhos, o que lhes seria muito difícil, levando em consideração a sua falta de recursos técnicos e económicos. Por outro lado, a prática de Salam Rejo de escrever a sua história cultural parou. Alguns dos jovens "historiadores" amadores deixaram a sua aldeia para prosseguirem estudos superiores e procurarem melhores oportunidades de emprego. As entrevistas realizadas aos participantes de ambas as oficinas (de história local e de cinema) revelaram que estes já não praticavam as suas competências de escrita (participantes masculinos e femininos, entrevista, 9/1/2019). O seu novo ambiente institucional não exigia nem apoiava a sua prática anterior. 
Podemos ver através dos exemplos que a prática cultural de narração de histórias, quer a nível pessoal, que a nível coletivo, preparou os membros da comunidade para participarem na produção de filmes. Permitiu e, ao mesmo tempo, estruturou as suas escolhas de acordo com o que é culturalmente aceitável e o modo como o fazer. Numa sociedade comunitária, contar a sua própria história é, se não houver coordenação, uma decisão pessoal e social. Muitas vezes, isto coloca os indivíduos na posição defensiva de tentar mitigar os estragos que a narração social fez à sua reputação. No entanto, as práticas de narração coletiva existentes também podem ser incorporadas nos processos de média participativos, para benefício da comunidade, logo que as competências e a narrativa sejam dominadas.

\section{VISIBILIDADE E CASTING SOCIAL}

O formato inicial deste estudo tinha como objetivo perceber como as pessoas usaram diferentes tecnologias para criar imagens, que depois usaram no seu discurso público sobre os seus receios comuns. No entanto, o inquérito e as observações revelaram que estas tecnologias foram usadas com pouca expressão na abordagem de questões públicas. Para além da falta de atenção como possível explicação para tal, um dos participantes sugeriu outra - bastante reveladora. O anterior líder da organização juvenil em Salam Rejo disse que não se atrevia a chamar a atenção para temáticas sociais por receio de incitar comentários negativos por parte de outros. Usou-a apenas para publicar notícias sobre eventos culturais como parte da sua função na administração da aldeia (participante masculino, entrevista, 9/1/2019). Devido a esta descoberta, os autores decidiram mudar a sua atenção para a questão relacionada com a forma como os participantes se tornaram visíveis para o público, dentro e fora da oficina de cinema. Esta questão é relevante por dois motivos. Uma é que para se tornar público requer a visibilidade dos agentes (Sorlin citado em Dayan, 2001, p. 746) e a outra razão é que o medium cinema é ele mesmo visual. Assim sendo, a visibilidade a olho nu e pelo olho da câmara constitui a participação em assuntos públicos através do cinema.

Os membros da comunidade de Elu Loda com necessidades especiais foram anteriormente colocados numa posição desfavorável, uma vez que haviam sido escondidos pelas suas famílias até à campanha iniciada por ativistas de uma ONG sete anos antes (participante feminina, entrevista, 13/11/2018; participante feminina, entrevista, 30/11/2018). Nem toda a gente se sentiu desencorajada pelo sentimento de vergonha da família e, pelo menos, um membro conseguiu receber educação básica, sustentar-se e constituir a sua própria família (participante masculino, entrevista, 27/11/2018). No entanto, de um modo geral, os membros da comunidade com necessidades especiais haviam permanecido relativamente invisíveis, com exceção de dois irmãos albinos. Sobressaíam em público e não tiveram qualquer inibição em participar em atividades públicas, somente afetadas pela sua hipersensibilidade à luz direta do sol, a qual abundava em Sumba. A comunidade via-os como "quase normais" porque, embora o seu cabelo e pele lhes parecessem fora do normal, a pele branca era valorizada a nível local. Além 
do mais, de alguma maneira estes irmãos haviam desenvolvido uma forma de vestir diferente e perfeitamente na moda quando comparada com os padrões da comunidade. $A$ vontade da jovem rapariga de partilhar uma descrição muito completa da sua história de vida e a sua pele albina, assim como a do seu irmão, juntamente com roupas na moda, tornaram-nos as estrelas do filme de Elu Loda. Poderíamos argumentar que não foi a sua aparência física que os tornou reconhecíveis, mas sim a sua diferença em relação aos outros, uma extensa construção cultural. Do ponto de vista teórico, a mesma condição, em contextos diferentes, poderia ter produzido resultados diferentes. Uma vez que este filme em particular contava histórias sobre pessoas com necessidades especiais, os irmãos estavam, mais do que os outros, assimetricamente posicionados para a participação. Com base na combinação entre a condição da sua pele e a prática competente de vestir, seria quase impossível não incluí-los.

Houve também outros exemplos de como a avaliação da aparência física é cultural e gerava uma predisposição especial em relação à oficina de cinema. O casting para o filme de Salam Rejo aconteceu ao mesmo tempo que o realizador foi urdindo os fios da história. À medida que o realizador elaborava os detalhes da história, desenvolvendo mais personagens e cenas, o elenco crescia. O objetivo do casting era ou moldar as personagens do filme para que fossem de encontro à pessoa real ou procurar uma pessoa que tivesse características semelhantes às da personagem. Geralmente, a equipa do filme optava pela primeira hipótese, uma vez que todos os atores e atrizes eram amadores. Contudo, no caso do filme de Salam Rejo, a equipa quis incluir uma personagem fictícia, alguém que ficasse bem à frente das câmaras e que emprestasse ao filme uma aparência moderna e fresca para que a questão da religião tradicional não ficasse associada negativamente a atraso e primitivismo. Inicialmente, escolheram uma jovem para interpretar a personagem, mas o modo como ela se apresentava não era considerado (suficientemente) moderno e fresco. Depois, pediram aos participantes na oficina que nomeassem os seus amigos e conhecidos. Em resposta, os participantes procuraram nas suas pastas de imagens e redes sociais no smartphone e apresentaram o que consideravam serem os candidatos adequados. Esta busca através de fotografias, para tentar descobrir aqueles que se considerava corresponderem aos critérios (com boa aparência e extrovertidos), e, em seguida, propor e discutir os candidatos novamente, mostra como a visibilidade e valores como boa aparência funcionam para abrir portas à participação. Durante o casting, a candidata escolhida provou ser hábil perante uma câmara, de acordo com o indicado através dos diversos artigos de roupa que podiam ser misturados e combinados para criar diferenças na sua aparência. Uma vez mais, aqui não se trata das suas qualidades intrínsecas, mas da sua relativa diferença em relação aos outros, e a forma como isto foi percebido e apreciado, o que tornou impossível ignorá-la.

\section{SER E PARTICIPAR EM COMUNIDADE}

De acordo com o que dissemos antes, uma característica partilhada por ambos os casos era o envolvimento dos participantes na vida comunitária, embora variasse em intensidade. Os participantes na oficina não abdicaram da sua condição social ao 
decidirem aderir à atividade; pelo contrário, uma vez dentro, floresceram e continuaram a tirar partido da sua posição social. A comunidade de Elu Loda havia, de alguma forma, resolvido o seu problema de inclusão de pessoas com necessidades especiais, pelo menos até ao ponto de nomearem uma delas como líder da associação do bairro e de as restantes estarem representadas nas consultas sobre planos para o desenvolvimento (desde a aldeia até à regência). Logo, os participantes com necessidades especiais estavam mais interessados nos aspetos técnicos da produção do que no tema do filme. Por exemplo, a capacidade de atuar sem ter memorizado os diálogos, decorrente da sua experiência em teatro, deixou alguns participantes bastante impressionados. Por outro lado, a comunidade de Salam Rejo começara apenas há dois anos a trabalhar a igualdade de oportunidades depois de uma colaboração bem sucedida com a administração da aldeia a propósito da publicação de um livro sobre história local. A comunidade penghayat começou igualmente a ser convidada para a elaboração dos planos das reuniões (uma vez mais, desde a aldeia até à regência). Contudo, subjacente a esta promissora mudança estava a falta de cooperação entre os aderentes à religião oficial e os crentes da religião tradicional. Enquanto que o processo de elaboração de histórias decorreu sem sobressaltos em Elu Loda, durante a oficina em Salam Rejo o processo foi mais demorado, com discussões mais intensas, formais e informais, entre o patrocinador, a comunidade e os profissionais de cinema. A discussão andou, sobretudo, à volta da questão de as histórias de amor acabarem ou não em ruturas, ou de uma crença ter de se submeter a outra. A solução liberal de deixar a questão para os indivíduos resolverem nunca foi uma opção. Isto porque as ruturas seriam interpretadas como uma promoção da exclusividade, e não da inclusividade, e a submissão seria interpretada como desigualdade entre crenças. Finalmente, concordou-se que o filme teria um final aberto para que o público pudesse levar a questão para casa em vez de reagir imediatamente a favor ou contra.

Os valores comunitários javaneses que dão prioridade à harmonia sobre o conflito aberto moldaram a forma como as relações igualitárias de poder funcionam. Concordamos com Menchik (2016) quando este afirma que as diferentes comunidades religiosas estão essencialmente ligadas através de uma relação agonista, pelo menos no que diz respeito às verdades que reclamam, mas na realidade os crentes querem que a sua vida social seja harmoniosa. Por exemplo, os penghayat não tiveram problemas em misturar os seus rituais com os dos protestantes. Preferem que a sua crença não conste dos documentos de identificação, apesar de a lei atual o permitir. Por que razão é tão importante debater esta questão em relação ao cinema participativo? Porque, durante a oficina, foi precisamente esta a questão referida como a mais importante para a comunidade de Salam Rejo. Segundo alguns participantes, tal questão continuou a ser importante após a produção do filme, de o resultado ter sido visto no ecrã e de os participantes "terem defendido o seu caso" de uma forma simbólica perante comunidades maiores. Isto vai para além de meros pormenores técnicos relacionados com a produção de filmes e de que até que ponto lhes é permitido participar no processo; tem a ver com a sua identidade e relação com a comunidade. Por outras palavras, a questão da participação em filmes comunitários envolve não só a forma como grupos, com diferentes posições nas 
relações de poder, trabalham em conjunto num projeto coletivo, mas também como as relações que mantêm com outros grupos, mais antagónicos, irão correr depois da oficina. Afinal, o desejo dos participantes era passar uma imagem positiva dos penghayat e não perturbar a harmonia das comunidades onde vivem. Do ponto de vista dos participantes, a sua integração nas relações sociais antes, durante e depois da oficina, com os seus colegas e as comunidades fora desse contexto, tem uma importância fundamental.

Depois das oficinas terminarem, os participantes voltaram a assumir as suas posições sociais, enquanto dirigentes da aldeia de Elu Loda, membros ou líderes da organização juvenil de Salam Rejo, ativistas de ONG ou residentes regulares numa das duas comunidades. Nestas capacidades ou papéis, já sabiam como se movimentar, negociar e acomodar os diferentes interesses em diversos contextos, tais como reuniões sobre planos para o desenvolvimento, organização de festivais, prestação de serviços públicos na aldeia e organização de protestos. As oficinas sobre cinema participativo forneceram-Ihes as competências técnicas e retóricas suplementares que podiam usar em objetivos individuais e/ou coletivos, como desenvolvimento económico e avanços na carreira, coesão de identidade, autorepresentação e diversão pela arte. Defendemos que a importância da participação deveria ser avaliada através destes critérios. E, se nos for permitido acrescentar, a uniformização do poder não é apenas uma medida formal (segundo a qual todos têm direito a voto) ou livre de cultura.

\section{Conclusão}

Este artigo defende que precisamos entender melhor as pré-condições que moldam a estrutura e dinâmica da participação. Os nossos dois estudos de caso exploraram as práticas culturais que ligam os indivíduos ao "mundo público", e foram três as descobertas essenciais que resultaram da nossa análise. A primeira diz respeito ao modo como as histórias pessoais circulavam nesses grupos comunitários e como alguns indivíduos usavam os filmes como um canal para divulgar os seus pontos de vista. As modalidades comunitárias de narração de histórias, usadas anteriormente na aldeia (teatro e escrita sobre história local) não ganharam muito com as oficinas, uma vez que os filmes não as usaram ou incluíram suficientemente, desligando-se das práticas de comunicação existentes. Em segundo lugar, estes dois casos de estudo demonstraram que a cultura moldou as oportunidades de visibilidade dos participantes e a forma como alguns desenvolveram as competências para se tornarem mais visíveis, o que acabou por facilitar a sua participação. Terceiro, o facto de os participantes pertencerem à sua cultura e comunidade transcendeu a moldura temporal dessas oficinas. Por outras palavras, havia uma vida comunitária antes e depois dos filmes. Isto teve influência sobre as coisas nas quais queriam participar, por que motivos e se estavam mais interessados em adquirir conhecimento técnico e/ou conteúdo. As práticas de narração de histórias, da possibilidade de se tornarem visíveis e de vida comunitária afetaram profundamente a posição dos membros da comunidade nas oficinas sobre cinema participativo. As comunidades marginalizadas e os facilitadores precisam de se comprometer com estas três práticas, a sós ou em colaboração com outros, para maximizar os benefícios do seu envolvimento 
em processos participativos. Tendo por base os nossos dois casos de estudo, defendemos que a participação deverá situar-se entre as práticas comunitárias mais alargadas e de longo termo para evitar que seja vista como um fim em si mesma, em vez de uma estrutura que permite alcançar objetivos individuais, comunitários e comuns.

Ao mesmo tempo, a nossa análise demonstrou que a participação de comunidades marginalizadas na produção de média continua a ser importante por duas razões. Em primeiro lugar, a sua participação dá a oportunidade ao mundo exterior de ouvir as suas vozes, o que de outra forma não seria tão autêntico ou exato, caso outros falassem por si. Em segundo lugar, os participantes adquirem novas competências que poderão usar mais tarde para negociar o seu relacionamento com grupos dominantes. Finalmente, quer o estudo sobre a participação, quer a investigação participativa são igualmente relevantes para a própria comunidade académica, uma vez que este tipo de análise mantém o estudo sobre os média, comunicação e cultura focado na perspetiva e nos interesses dos participantes. Obriga-nos a relembrar o verdadeiro objetivo da nossa investigação.

\section{Tradução: Helena Antunes}

\section{REFERÊNCIAS}

Arnstein, S. R. (1969). A ladder of citizen participation. Journal of the American Planning Association, 35, 216224. http://dx.doi.org/10.1080/01944366908977225

Carpentier, N. (2011a). Media and participation: a site of ideological-democratic struggle. Bristol \& Chicago: Intellect.

Carpentier, N. (2011b). The concept of participation: if they have access and interact, do they really participate? Communication Management Quarterly, 6, 13-36.

Carpentier, N. (2016). Beyond the ladder of participation: an analytical toolkit for the critical analysis of participatory media processes. Javnost - The Public, 23, 70-88. https://doi.org/10.1080/13183222.2016.11 49760

Couldry, N., Livingstone, S. \& Markham, T. (2007). Media consumption and public engagement: beyond the presumption of attention. Hampshire: Palgrave MacMillan.

Crouch, M. (2016). Legislating inter-religious harmony. Attempts at reform in Indonesia. In T. Lindsey \& $\mathrm{H}$. Pausacker (Eds.), Religion, law and intolerance in Indonesia (pp. 95-112). Londres: Routledge.

Dagron, A. G. (2007). Call me impure: myths and paradigms of participatory communication. In L. Fuller (Ed.), Community media: international perspectives (pp. 197-208). Nova lorque: Palgrave MacMillan.

Dayan, D. (2001). The peculiar public of television. Media, Culture Q Society, 23, 743-765. https://doi. org/10.1177/016344301023006004

Dahlgren, P. (2003). Reconfiguring civic culture in the new media milieu. In J. Corner \& D. Pels (Eds.), Media and the restyling of politics (pp. 151-170). Londres: Sage. 
Dahlgren, P. (2006). Doing citizenship: the cultural origins of civic agency in the public sphere. European Journal of Cultural Studies, 9, 267-286. https://doi.org/10.1177/1367549406066073

della Porta, D. (2013). Can democracy be saved? Participation, deliberation and social movements. Cambridge: Polity Press.

Evans, M., Foster, M., Corbett, J., Dolmage, E., Gervais, J., Raquel, M. \& Romano, Z. (2009). Representation in participatory video: some considerations from research with métis in British Columbia. Journal of Canadian Studies, 43(1), 87-108.

Gutberlet, J. (2008). Empowering collective recycling initiatives: video documentation and action research with a recycling co-op in Brazil. Resources, Conservation Q Recycling, 52, 659-670.

Jenkins, H. \& Carpentier, N. (2013). Theorizing participatory intensities: a conversation about participation and politics. Convergence: The International Journal of Research into New Media Technologies, 19, $265-286$. https://doi.org/10.1177/1354856513482090

Kunci Cultural Studies Center and Engage Media. (2009). Videochronic: video activism and video distribution in Indonesia. Research Report. Retirado de https://www.engagemedia.org/videochronic-english

Menchik, J. (2016). Islam and democracy in Indonesia: tolerance without liberalism. Nova lorque: Cambridge University Press.

Mistry, J., Bignante, E. \& Berardi, A. (2014). Why are we doing it? Exploring participant motivation within a participatory video project. Area, 48, 412-418.

Muhtadi, B. (2018). Komoditas demokrasi: efek sistem pemilu terhadap maraknya jual beli suara. In M. Sukmajati \& A. Perdana, Pembiayaan Pemilu di Indonesia (pp. 95-117). Jacarta: Bawaslu (The Elections Supervisory Board).

Mutaqin, Z. Z. (2014). Penghayat, orthodoxy and the legal politics of the state. Indonesia and the Malay World, $42,1-23$.

Nurhasim, M. (2014). Partisipasi pemilih pada pemilu 2014: studi penjajakan. Report. Jacarta: KPU (The General Elections Commission).

Postill, J. (2010). Introduction: theorising media and practice. In B. Bräuchler \& J. Postill, Theorising media and practice (pp. 1-32). Nova lorque: Berghahn Books.

Shaw, J. (2016). Emergent ethics in participatory video: negotiating the inherent tensions as group processes evolve. Area, 48, 419-426.

Singh, N., High, C., Lane, A. \& Oreszczyn, S. (2017). Building agency through participatory video: insights from the experiences of young women participants in India. Gender, Technology Q Development, 21, 173188. https://doi.org/10.1080/09718524.2018.1434993

Törnquist, O. (2013). Assessing the dynamics of democratisation: transformative politics, new institutions, and the case of Indonesia. Nova lorque: Palgrave Macmillan.

Yüksek, D. \& Carpentier, N. (2018). Participatory contact zones and conflict transformation. The participatory intensities of the Cyprus Friendship Program. Conjunctions. Transdisciplinary Journal of Cultural Participation, 5(1), 1-21. https://doi.org/10.7146/tjcp.v5i1.105286 


\section{NOTAS BIOGRÁFICAS}

Kurniawan Adi Saputro é Doutorado em Ciências da Comunicação pela Universidade de Sheffield Hallam, no Reino Unido. Entre os interesses de investigação constam tema como a análise do envolvimento das audiências, em diversos contextos, especialmente em ambientes de crise. Professor no Departamento de Fotografia e da Faculdade de Média, no Instituto de Artes, em Jacarta, na Indonésia.

ORCID: https://orcid.org/0000-0002-5202-0017

Email: kurniawan.as@isi.ac.id

Morada: Jl. Suryodiningratan No. 8, Yogyakarta 55143, Indonésia

Bari Paramarta Islam é investigador independente na área da literacia visual, desenvolvendo trabalho em escolas secundárias através da utilização da fotografia.

ORCID: https://orcid.org/oooo-0003-3744-9840

Email: paramartabari@gmail.com

Morada: Tawangsari RT O2 RW O2, Kadilanggon Wedi, Klaten, Indonésia

* Submetido: 08/02/2019

$*$ Aceite: 08/05/2019 